\title{
The effects of electricity tariffs on cost-minimal hydrogen supply chains and their impact on electricity prices and redispatch costs
}

\author{
Frederik vom Scheidt \\ Karlsruhe Institute of Technology \\ frederik.scheidt@kit.edu
}

\author{
Jingyi Qu \\ Karlsruhe Institute of Technology \\ jingyi.qu@kit.edu
}

\author{
Philipp Staudt \\ Karlsruhe Institute of Technology \\ philipp.staudt@kit.edu
}

\author{
Dharik Mallapragada \\ Massachusetts Institute of Technology \\ dharik@mit.edu
}

\begin{abstract}
Hydrogen fueled transportation can contribute substantially to the reduction of global carbon emissions. However, the production of hydrogen through electrolysis creates interdependencies with electricity systems. Therefore, we present a new model which couples the hydrogen supply chain with the electricity system. We use this model to analyse a case study of Germany in 2030. We find that if efficient spatially resolved electricity tariffs are applied instead of existing uniform tariffs, electrolyzers are placed primarily at low-cost nodes and farther away from consumption centers. For hydrogen, this leads to higher transportation costs, but lower production costs, and lower total costs. Moreover, costs for congestion management decrease substantially.
\end{abstract}

\section{Introduction}

To limit the global increase in temperature to $1.5^{\circ} \mathrm{C}$ compared to 1990 levels, greenhouse gas (GHG) emissions must be reduced to net-zero in the next three decades. In this endeavour, the transportation sector's GHG emissions are of major importance, as they amount to $15 \%$ of global energy related emissions and continue to rise [1]. Within the sector, passenger road vehicles and road freight vehicles account for $44 \%$ and $30 \%$ of emissions, respectively [2]. In both of these sub-sectors, hydrogen Fuel Cell Electric Vehicles (FCEVs) can contribute to emission reductions by substituting fossil fuel vehicles. The German government aims to meet its 2030 reduction goals [3] partly by building up a national hydrogen supply chain including domestic electrolysis, fueling stations, and transportation [4].

The planning of such capital-intensive and long-term infrastructure requires thorough and holistic system analysis. From the point of view of the electricity

\author{
Christof Weinhardt \\ Karlsruhe Institute of Technology \\ christof.weinhardt@kit.edu
}

system, electrolyzers are new, large consumers which might increase network flows in the system and lead to higher congestion costs if placed amiss. Moreover, electrolyzers are long-term installations with typical lifetimes of ten years [5]. Once they are installed, their effects on the system will persist for years. As infrastructure investment decisions for 2030 are being made today, a thorough analysis of the effects of hydrogen supply chains on the electricity system is needed. The European Commission has recognized this and is calling for efficient and competitive regulation that provides price signals to electrolyzers that reflect their impact on energy system costs [6].

Therefore, we aim to advance this research field by making three contributions. First, we expand the vehicle-type-specific focus of prior studies by including both passenger cars and freight transportation in our analysis. We develop a mixed-integer linear programming model to evaluate the cost-optimal hydrogen supply chain with explicit consideration of geographical distribution of hydrogen demand and electrolyzer locations. Second, we analyze the effect of two different electricity tariffs on the optimal supply chain design and hydrogen end-use costs. We calculate a reference uniform tariff scenario based on the system-wide market clearing price to reflect current regulation in most European countries. We compare this scenario with a nodal tariff based on simulated locational marginal shadow prices. Third, we feed back those results and measure how hydrogen production changes electricity wholesale prices and grid congestion costs. In the next section, we begin by reviewing related literature and describing prevailing research gaps.

\section{Related work}

Early work on spatially resolved hydrogen supply chain models targeting the transportation sector focuses on hydrogen production from steam methane reforming, 
coal and biomass gasification $[7,8,9]$. During the last decade, research focus shifted to hydrogen production from electrolysis, investigating the effects of resource availability [10, 11, 12], emission pricing [13], and hydrogen storage [14]. However, these studies do not regard the interaction of hydrogen supply chains with the existing electricity grid.

Linking the hydrogen supply chain with the national electricity grid, [15, 5, 16] analyze scenarios of widespread diffusion of hydrogen-fueled passenger cars in Germany in 2050. Compared to earlier work, they increase the spatial granularity of analysis to the 402 districts in Germany which equals the third level of the Nomenclature of Territorial Units for Statistics (NUTS-3) [17]. [18] analyze the costs of hydrogen stored in liquid organic hydrogen carrier (LOHC) material and synthetic fuels for passenger cars. In one scenario, the authors calculate a representative nodal price for two exemplary states in Germany and allow transportation of hydrogen between the two states. This leads to higher hydrogen production in the state with lower price. Besides the limitation of state-level spatial granularity, the authors note that analyzing feedback effects on the electricity system represents important future work. [19] address the optimal location of hydrogen fueling stations for $100 \%$ heavy-duty freight trucks on German highways in 2050, using an electricity system planning model and truck driving data. They exclusively regard on-site electrolysis at the stations and find that this hinders the optimal usage of low-price locations and increases transmission congestion. [20] optimize the operation of a $1 \mathrm{MW}$ electrolyzer over a set of 7182 electricity tariffs in the USA. They find that hydrogen production costs can be reduced through flexible operation with dynamic tariffs. However, spatial differences in electricity prices across the USA have a larger effect on end-use costs than dynamic operation.

In summary, past research has repeatedly found that electricity costs have a large impact on end-use hydrogen costs. It has also found initial evidence that spatially differentiating electricity prices influences the optimal location of production. However, past studies have so far largely neglected the following aspects.

First, existing studies have either focused on hydrogen demand from passenger cars or from heavy-duty freight vehicles. This neglects large shares of GHG emissions and potentially distorts their findings. Therefore, we pose Research Question (RQ) 1: What is the cost-minimal supply chain design for the combined hydrogen demand from passenger cars and heavy-duty trucks in 2030 in Germany?

Second, to the best of our knowledge, no study has assessed the impact of tariffs with different spatial granularities on a nation-wide level. This results in RQ2: What is the impact of uniform and nodal electricity tariff designs on cost-minimal hydrogen supply chains and the total costs of hydrogen?

Third, the feedback effects of hydrogen production on the electricity system have received limited attention in the past. The electricity system, particularly in Germany, is already facing challenges of grid congestion due to increasing integration of fluctuating renewable sources and spatial imbalances of generation and consumption [21]. This can be exacerbated by the large scale deployment of hydrogen production for FCEVs. To address this, we answer RQ3: What are the feedback effects of hydrogen production on electricity wholesale prices and congestion management costs under uniform and nodal tariffs?

\section{Methodology}

To address the research questions above, we model the hydrogen supply chain and the electricity system. We then parametrize both models with data for the German transportation and electricity sector in 2030. We first parametrize and run the electricity model to compute uniform and nodal electricity prices - as input variables for the hydrogen model - as well as benchmark redispatch costs. Second, we run the hydrogen model to minimize total costs of the integrated hydrogen supply chain through optimal spatial siting and sizing of electrolyzers and optimal hydrogen delivery. Third, we feed back the results as additional regional loads from the electrolyzers into the electricity model and calculate consequential changes in electricity prices and redispatch costs. Both models are implemented in Python 3.7.3, using the Gurobi solver 8.1.1. For the data preparation of our hydrogen supply chain model, we use the Python packages Pandas, NumPy, and Shapely; to visualize the geographical distribution of electrolyzers and nodal prices, we use GeoPandas, and Matplotlib.

\subsection{Hydrogen supply chain model}

In the following, we describe the objective function and constraints of the hydrogen supply chain model.

\subsubsection{Objective function}

The model minimizes the total costs of the hydrogen supply chain, which consists of capital costs and operating costs for the production (PCC, POC), conversion (CCC, COC), fueling stations (SCC, SOC) and transportation (TCC, TOC), as shown in Equation (1). There are three decision variables which are represented in bold. $X_{p}$ indicates if an electrolyzer is installed at a location $p$ or not $\left(X_{p} \in\{0,1\}\right) . \quad Y_{p, i}$ 
indicates if hydrogen is transported from a location $p$ to a fueling station $i\left(Y_{p, i} \in\{0,1\}\right) . P$ and $I$ represent the set of all potential electrolyzer plant locations $p$, and hydrogen fueling stations $i$, respectively. The third decision variable is continuous $\left(H P_{p} \in[0, \infty)\right)$ and denotes the daily amount of hydrogen produced at location $p\left[\mathrm{~kg}_{\mathrm{H}_{2}}\right]$. The model is run for three possible states $s$ in which hydrogen can be transported via delivery trucks, namely gaseous (GH2), liquefied (LH2), and bound in LOHC.

$$
\begin{array}{r}
\min _{X_{p}, H P_{p}, Y_{p, i}}\left(\sum_{p \in P} P C C_{p}\left(\boldsymbol{X}_{\boldsymbol{p}}, \boldsymbol{H} \boldsymbol{P}_{\boldsymbol{p}}\right)+C C C_{s}\right. \\
+S C C_{s}+T C C_{s}+\sum_{p \in P} P O C_{p}\left(\boldsymbol{X}_{\boldsymbol{p}}, \boldsymbol{H} \boldsymbol{P}_{\boldsymbol{p}}\right) \\
+\sum_{p \in P} C O C_{p, s}\left(\boldsymbol{X}_{\boldsymbol{p}}, \boldsymbol{H} \boldsymbol{P}_{\boldsymbol{p}}\right)+S O C_{s} \\
\left.+\sum_{p \in P} \sum_{i \in I} T O C\left(\boldsymbol{Y}_{\boldsymbol{p}, \boldsymbol{i}}\right)\right)
\end{array}
$$

All four components of capital costs include specific annual $O \& M$ costs, and annuity factors $(A F)$. The annuity factors account for the depreciation of one-time investments over multiple years and depend on weighted average cost of capital (WACC [\%]) and the individual depreciation years ( $d[-])[22]$, as shown in Equation (2).

$$
A F=\frac{(1+W A C C)^{d} * W A C C}{(1+W A C C)^{d}-1}
$$

The electrolyzer capital costs are made up of the capacity dependent investment costs $I E$ $\left[€ / k W_{e l}\right]$, multiplied by hydrogen's energy density $E D$ $\left[k W h_{H_{2}} / k g_{H_{2}}\right]$, and the constant hydrogen production $H P_{p}\left[k g_{H_{2}}\right]$, divided by the full load hours $F L H[\mathrm{~h}]$ and electricity efficiency $E E\left[k W h_{H_{2}} / k W h_{e l}\right]$ (3). Conversion capital costs depend on capacity-specific investment costs $\left(I C\left[€ / k_{H_{2}}\right]\right)$, the sum of converted hydrogen across all plants $\left(\left[\mathrm{kg}_{\mathrm{H}_{2}}\right]\right)$, and state $s$ (4). Fuel station capital costs equal the investment costs of one fueling station $(I S[€])$ multiplied with the number of fueling stations (NFS [-]) (5). Transportation capital costs equal the number of trucks and trailers $(N T[-])$, multiplied with the respective investment per truck $(\operatorname{ITRU}[€])$ and trailer $(\operatorname{ITRA}[€])(6)$.

$$
\begin{gathered}
P C C_{p}=\frac{I E * E D * H P_{p}}{F L H * E E} \\
*\left(1+O \& M_{E}\right) * A F_{E} \\
C C C_{s}=I C_{s} *\left(1+O \& M_{C_{s}}\right) * A F_{C}
\end{gathered}
$$

$$
\begin{array}{r}
S C C_{s}=I S_{s} * N F S *\left(1+O \& M_{S_{s}}\right) * A F_{S} \\
T C C_{s}=I T R U * N T *\left(1+O \& M_{T R U}\right) \\
* A F_{T R U}+I T R A_{s} * N T \\
*\left(1+O \& M_{T R A_{s}}\right) * A F_{T R A}
\end{array}
$$

The production operating costs of each electrolyzer depend on its daily hydrogen output $\left(\mathrm{HP}_{p}\left[\mathrm{~kg}_{\mathrm{H}_{2}}\right]\right)$, the electricity consumption (ECP $\left.\left[k W h_{e} l / k g_{H_{2}}\right]\right)$ and the location-specific electricity price $\left(E P_{p}\right.$ $\left.\left[€ / k W h_{e} l\right]\right)(7)$. Similarly, the conversion operating costs depend on daily hydrogen throughput $\left(H P_{p}\right.$ $\left.\left[k g_{H_{2}}\right]\right)$, the electricity required for conversion $(E C C$ $\left.\left[k W h_{e} l / k g_{H_{2}}\right]\right)$ and the electricity price $\left(E P_{p}\right.$ $\left.\left[€ / k W h_{e} l\right]\right)(8)$. The fueling station operating costs are formed by the output-dependent consumption of electricity (ECS $\left.\left[k W h_{e} l / k g_{H_{2}}\right]\right)$ and natural gas $\left(G C S\left[k W h_{N} G / k g_{H_{2}}\right]\right)$ ), and the respective prices (EP $\left[€ / k W h_{e} l\right]$, and NGP $\left[€ / k W h_{N} G\right]$ ) (9). Last, the transportation operating costs (10) are made up of the transport distance between matched electrolyzers and fueling stations $\left(T D_{p, i}[\mathrm{~km}]\right)$, fuel consumption (FCT $[\mathrm{l} / \mathrm{km}])$, fuel price $(F P[€ / l])$, and toll $(T C$ $[€ / k m])$. We approximate distances via air-line distance and account for this heuristic by multiplying with a detour factor of 1.3, in line with [23]. Besides, fixed annual labor costs $(L C[€])$ are added.

$$
\begin{gathered}
P O C_{p}=H P_{p} * E C P * E P_{p} * 365 \\
C O C_{p, s}=H P_{p} * E C C_{s} * E P_{p} * 365 \\
S O C_{s}=\left(E C S_{s} * E P+G C S_{s} * N G P\right) \\
* \sum_{p \in P} H P_{p} * 365 \\
((F C T * F P)+T C) * 1.3 * 365+L C
\end{gathered}
$$

\subsubsection{Constraints}

The sum of daily hydrogen production $H P$ must satisfy an exogenously given demand $H D$ (11). The hydrogen output $H P_{p}$ of each electrolyzer depends on its installed capacity, which lays between a fixed minimum and maximum value $H P C A P$. Hydrogen output can only be non-zero if an electrolyzer is installed at the respective location (12). The daily transportation volume $H T$ between an electrolyzer $p$ and a fueling station $i$ is set equal to the capacity of a fueling station $\left(S C A P_{i}\right)$. Non-zero transportation is only possible if the transportation between $p$ and $i$ is established (13). In sum, the daily amount of hydrogen transported from an electrolyzer to all fueling stations must not exceed the 
production at this electrolyzer (14). The entire demand of a fueling station is covered by one plant (15).

$$
\begin{gathered}
H D \leq \sum_{p \in P} H P_{p} \\
H P C A P_{\min } * X_{p} \leq H P_{p} \\
\leq H P C A P_{\max } * X_{p} \quad \forall p \in P \\
H T_{p, i}=S C A P_{i} * Y_{p, i} \quad \forall p \in P, i \in I \\
\sum_{i \in I} H T_{p, i} \leq H P_{p} \quad \forall p \in P \\
\sum_{p \in P} Y_{p, i}=1 \quad \forall i \in I
\end{gathered}
$$

\subsection{Hydrogen supply chain data}

In this subsection, we present the data sources, preprocessing steps, and assumptions we use to create the input data for demand, production, and transportation of hydrogen. For all steps of the supply chain, WACC is set to $4 \%$, adopted from [24].

\subsubsection{Hydrogen demand data}

In the first step, we estimate total national hydrogen demand in the transport sector and the number of fueling stations required to satisfy the demand. In the second step, we spatially disaggregate this total demand and determine potential sites of fueling stations. Because of the different refueling habits, the locations of fueling stations for passenger cars and trucks are determined separately.

A 2019 study by the Fraunhofer-Institute [25] estimates the hydrogen demand for fuel cell passenger cars and trucks in Germany by 2030 . We assume that heavy-duty trucks with a total weight above $12,000 \mathrm{~kg}$ [26] will be responsible for all truck based demand, because of their high share in transport sector emissions [27] and clearer advantages compared to battery based heavy-duty trucks [28]. Since these estimates have been calculated, Germany's [4] and the European Union's [6] hydrogen strategies have been published, which both strongly promote the usage of hydrogen in the transportation sector. Therefore, we use the upper bound of hydrogen demand estimates from [25], shown in Table 1. We assume the consumption of hydrogen cars to decrease to $0.63 \mathrm{~kg} / 100 \mathrm{~km}$, and that of trucks to $14 \mathrm{~kg} / 100 \mathrm{~km}$ until 2030 . These values are in line with [27], and [29], respectively, and depend on future development of FCEV technology. Annual average mileage values for cars and trucks are adopted from the
German Federal Motor Transport Authority [30]. By dividing the total demand by the per-km consumption and annual mileage, we arrive at the estimated number of FCEVs. Comparing these numbers to the numbers of registered vehicles in 2019 [31] gives the respective penetration rates. All data are shown in Table 1.

Table 1: Estimated FCEV demand data for 2030

\begin{tabular}{lll}
\hline & Passenger cars & Trucks \\
\hline Annual Demand & $7 T W h_{H_{2}}$ & $2 T W h_{H_{2}}$ \\
Fuel consumption & $0.63 \mathrm{~kg} / 100 \mathrm{~km}$ & $14 \mathrm{~kg} / 100 \mathrm{~km}$ \\
Annual mileage & $14,000 \mathrm{~km}$ & $40,000 \mathrm{~km}$ \\
Penetration & $2,381,190$ & 10,715 \\
Penetration rate & $5.2 \%$ & $4.9 \%$ \\
\hline
\end{tabular}

To select potential hydrogen fueling stations in the next step, we break down the total demand to NUTS-1 (federal state) level by assuming each NUTS-1 region has the same share of FCEV penetration. The hydrogen fueling stations in our model supply compressed gaseous hydrogen at 700 bar to fuel cell passenger cars [32] and at 350 bar to fuel cell heavy-duty trucks [33]. Most of the existing hydrogen stations currently registered are small size with a capacity of $212 \mathrm{~kg} / \mathrm{day}$ [34]. We assume that by 2030 all hydrogen stations will become L-size [35] with a capacity of $1,000 \mathrm{~kg} /$ day. Since stations are not operating at full capacity all the time, we assume a utilization of $70 \%$. Thus, the turnover of each station $\left(S C A P_{i}\right)$ is 700 $\mathrm{kg} /$ day. Adopted from [5], station investment cost is estimated considering scaling and learning effects (16). At $\mathrm{n}=400$ stations, capacity $\mathrm{C}=1,000 \mathrm{~kg} / \mathrm{day}$ and the exogenous parameters $\alpha, \beta$, and $\gamma$ presented in Table 2 , we derive investment cost per station for each hydrogen transportation state $s(s \in\{G H 2, L H 2, L O H C\})$.

$$
\begin{array}{r}
I S_{s}=1.3 * 600,000 E U R * \gamma *\left(\frac{C}{212 k g / d a y}\right)^{\alpha} \\
*(1-\beta)^{\log _{2}\left(\frac{C * n}{212 k g / d a y * 400}\right)}
\end{array}
$$

Next, we identify potential locations of fueling stations to meet the demand in each NUTS-1 region.

For passenger cars, there are 72 hydrogen fueling stations (October 2019) in Germany [36]. Since these will not suffice to satisfy demand in 2030, we assume that additional fueling stations will be installed at the same locations as existing gasoline stations. Therefore, we use the 11,285 gasoline stations from OpenStreetMap as further potential sites [37]. Next, we assign the population in each NUTS-3 region to its nearest station location [38]. Stations with highest 
Table 2: Hydrogen station assumptions

\begin{tabular}{llll}
\hline & GH2 & LH2 & LOHC \\
\hline$\alpha[-]$ & 0.7 & 0.6 & 0.66 \\
$\beta[-]$ & 0.06 & 0.06 & 0.06 \\
$\gamma[-]$ & 0.6 & 0.9 & 1.4 \\
ECS $\left[k W h_{e l} l k g_{H_{2}}\right]$ & 1.6 & 0.6 & 4.4 \\
GCS cons. $\left[k W h_{N G} / k g_{H_{2}}\right]$ & 0 & 0 & 11.7 \\
Depreciation years $[a]$ & 10 & 10 & 10 \\
O\&M [\%] & 5 & 5 & 5 \\
\hline
\end{tabular}

associated population are selected until total hydrogen demand from cars is covered in each NUTS-1 region.

While passenger cars are usually filled up at a nearby station, trucks are mostly refueled along highways. Therefore, truck fueling stations are situated based on their distance to highways. We calculate the distance between stations and the nearest highway [39] and select stations from short to long distance until demand is met.

\subsubsection{Hydrogen production data}

Electrolysis utilizes electricity ("power") to split water into hydrogen and oxygen ("gas"). This power-to-gas process is at the center of long-term political strategies for low-carbon hydrogen supply in Germany [4] and the European Union [6]. We therefore focus on electrolysis for hydrogen production. Among the existing electrolysis technologies, proton exchange membrane (PEM) electrolysis shows a high technology readiness level, high potential for cost reduction and efficiency improvement [40] as well as high operational flexibility [41]. Therefore, our work focuses on PEM electrolysis. We assume investment costs $I E$ of 604 $€ / k W_{e l}$, depreciation over 10 years, O\&M costs of $4 \%$ of investment costs and an electricity consumption of $47.6 \mathrm{kWh} h_{e l} / \mathrm{kg}_{\mathrm{H} 2}$, based on $[42,43,5]$. Although the commercialization of large-scale PEM is still at an early stage, the demand for larger systems is growing rapidly [44]. We set the minimum capacity $H P C A P_{\min }$ to $10 \mathrm{MW}$ and the maximum $H P C A P_{\max }$ to $60 \mathrm{MW}$, according to [45]. All electrolyzers operate at $70 \%$ of full capacity (in line with the ranges of full load hours assessed in $[15,20])$ and at an efficiency of $70 \%[15,5]$. The energy density of hydrogen is $33.33 \mathrm{kWh} \mathrm{h}_{2} / \mathrm{kg}_{\mathrm{H}_{2}}$.

We set the nodes from the electricity system model (compare Section 3.4.1) as potential locations of electrolyzers. The employed model represents the transmission grid and does not consider the distribution grid, due to lack of data availability and high computational complexity. Thus, we assume that electrolyzers will be connected to transmission grid nodes.

\subsubsection{Hydrogen transportation data}

Since related work indicates hydrogen transport via pipelines only becomes economical for high demand scenarios in 2050 [5], we focus on transportation via delivery trucks. Because of hydrogen's low density it is commonly compressed (GH2), liquefied (LH2), or stored into LOHC for transportation. Conversion assumptions are adopted from [23] and are presented in Table 3. The variable $x$ denotes the desired output of hydrogen. In the next step, hydrogen is filled into trailers and transported to fueling stations via delivery trucks. Diesel consumption of a delivery truck is 34.1 $l_{\text {diesel }} / 100 \mathrm{~km}$ [46]. Besides fuel costs, we also include toll $(0.15 € / \mathrm{km})$ and labor costs $(69,300 € /$ year $)$ for the transportation, based on [23]. We assume trailer costs of $600 € / \mathrm{kg}$ for $\mathrm{GH} 2,200 € / \mathrm{kg}$ for $\mathrm{LH} 2$, and 93 $€ / \mathrm{kg}$ for LOHC in line with [23]. To fully utilize the capacity of each trailer, we set trailer capacity to $700 \mathrm{~kg}$. This is somewhat lower than what is technically possible $[23,47]$, but exactly meets the demand of one entire fueling station. Besides, we assume depreciation over twelve years and O\&M costs of $2 \%$, adopted from [5]. For trucks, investment costs of $160,000 €$, depreciation over eight years, and 12\% O\&M costs are assumed [5].

Table 3: Conversion assumptions, adopted from [5]

\begin{tabular}{|c|c|c|c|}
\hline & \multicolumn{3}{|c|}{ Investment $[€]$} \\
\hline Liquefaction & \multicolumn{3}{|c|}{$1.05 * 10^{8} *\left(\frac{x}{50 \frac{t_{H_{2}}}{H}}\right)^{0.66}$} \\
\hline Hydrogenation & \multicolumn{3}{|c|}{$4.0 * 10^{7} *\left(\frac{x+\frac{x}{d a y}}{300 \frac{t_{H} H_{2}}{d a y}}\right)^{0.66}$} \\
\hline Compressor & \multicolumn{3}{|c|}{$15,000 \frac{E U R}{k W} * x^{0.6089} * 3$} \\
\hline & $\begin{array}{l}\text { Depreciation } \\
\text { years }\end{array}$ & O\&M & $\begin{array}{l}\text { Electr. cons. } \\
{\left[k W h_{e l} / k g_{H_{2}}\right.}\end{array}$ \\
\hline Liquefaction & 20 & $4 \%$ & 6.78 \\
\hline Hydrogenation & 20 & $3 \%$ & 0.37 \\
\hline Compressor & 15 & $4 \%$ & calculated \\
\hline
\end{tabular}

\subsection{Electricity system model}

Next, we model the electricity system to simulate electricity prices as input for the hydrogen model, and to later measure feedback effects.

For the uniform tariff scenario, we employ a merit-order model of the electricity wholesale market. This model minimizes the hourly marginal generation costs for the entire market area. Its constraints ensure the hourly balancing of demand and supply and consider the limits of available generation capacity. Like the real market design in Germany, this merit-order model does not consider grid constraints. Therefore, the allocation 
can be technically infeasible, in which case redispatch is performed by the system operators. The redispatch mechanism starts with the merit-order market allocation and finds a new feasible cost-minimal solution that respects grid constraints, by adequately activating and deactivating generation capacity. Newly activated generators are compensated based on their operating and opportunity costs. The additional costs caused by this procedure are referred to as redispatch costs. Each hour is optimized step-wise, independently of other hours. For the detailed mathematical formulation of uniform price and redispatch calculation we refer to [48].

For the nodal tariff scenario, we adopt and adapt the model framework ELMOD, in particular its implementation for the German wholesale electricity market. The model is a nodal DC-load flow model with a granular spatial representation of the transmission system. For the full mathematical notation, we refer to the ELMOD documentation [49].

We parametrize both electricity price models with data for generation, consumption and the transmission grid. This data needs to be granular both in the temporal and spatial dimension, and needs to be estimated for the scenario year 2030 .

\subsection{Electricity system data}

The data sources and preprocessing steps for the input data for the electricity system model are described in this subsection. All data are published as supplementary material, together with a more detailed documentation [50].

\subsubsection{Transmission grid data}

To model the electricity grid for 2030, we start with data of the existing grid from an open source grid reference model [51]. We add data on transmission lines which are planned to be expanded or newly built until 2030, based on the grid development report of the Federal Network Agency [52]. Each existing or planned line has one start and one end node with a specific name. To retrieve the coordinates of each node, we use the Google Maps API. Following related literature, we approximate the transmission capacity of all $220 \mathrm{kV}$ lines to be $490 \mathrm{MW}$, and that of all $380 \mathrm{kV}$ lines to be $1700 \mathrm{MW}[49,53]$. Multiple lines between two nodes are aggregated into one by summing up the capacity value. The resulting transmission grid representation has 485 nodes and 663 lines.

\subsubsection{Electricity demand data}

To model electricity consumption, we derive the hourly consumption forecast scenario EUCO30 for Germany in 2030 from the European Network of Transmission System Operators for Electricity (ENTSO-E) [54]. This scenario is available for three different weather scenarios, based on the weather in the years 1982 ("dry"), 1984 ("normal") and 2007 ("wet"). We average the demand values from these three scenarios to avoid using a demand scenario that is particularly inconsistent with our renewable generation input data, which is only available for more recent years. This averaging presumably smoothes out fluctuations in demand and prices. Last, we re-scale the hourly demand values so that the annual sum (577 TWh) equals the sum used in the grid development plan (544 TWh) [52], to improve consistency of grid and demand data.

Next, we spatially disaggregate the hourly demand values. We follow the top-down methodology of Robinius [55] and Egerer et al. [49] which is based on the gross domestic product (GDP) and the population of a region as proxies for its electricity consumption. First, we derive the NUTS-2 (government regions) load shares based on available 2030 forecasts for NUTS-2 GDP [56]. Second, we break down the load shares by assuming that the demand share of each NUTS-3 (district) is proportional to the share of population within its NUTS-2 region. Third, we assign all NUTS-3 demand shares to their nearest grid nodes with the Haversine formula, based on their coordinates.

\subsubsection{Electricity generation data}

We derive hourly generation data from solar and wind for 2016, 2017 and 2018 from the four national grid operators [57] and calculate an average year. Then, we re-scale the hourly generation values of each technology so that the annual sum equals the sum used in the 2030 grid development plan [52]. Next, we spatially disaggregate hourly generation values. For this, we use the national register for renewable power plants, which provides installed generation capacity for each zip code [58]. We assign hourly generation to zip codes in proportion to their installed capacity. In sum, we assume an annual electricity generation of 86.7 TWh from PV, compared to an average of 35.34 TWh in 2016-2018, and of 247.4 TWh from wind, compared to an average of 108.6 TWh in 2016-2018.

For dispatchable fuel-based electricity generation capacity, we use the power plant list provided by the German grid regulator [59]. We filter out all relevant plants for 2030. Next, we derive marginal costs for each plant based on its fuel costs, efficiency, and emissions costs, as described in [50].

Then, we match each renewable and fuel-based power plant to the nearest node with the Haversine formula based on their coordinates. For combined heat and power plants (CHP) under $10 \mathrm{MW}$ - which in sum 
amount to $8.4 \mathrm{GW}$ - no geographical information is given. Since regional CHP capacity is correlated with electricity demand [60], these plants are assigned to nodes with the same method as the demand.

\section{Results}

After parametrizing the hydrogen and electricity model as described above, we derive the results which we outline in this chapter.

\subsection{Electricity system results}

First, we use the electricity model to calculate uniform and nodal prices, as well as redispatch costs under the uniform pricing scheme. The resulting annual average of the uniform price in 2030 is 62.61 $€ / \mathrm{MWh}$. Under nodal pricing, the annual average price at different nodes varies between -54.30 and 221.00 $€ / M W h$, with a median value of $67.80 € / M W h$. Low prices are predominantly found in Northern Germany, where much renewable generation capacity is installed. Figure 1c displays the spatial distribution of nodal prices. Annual redispatch costs are 6.16 Bn€.

\subsection{Hydrogen supply chain results}

Next, we use the electricity prices as input variables for the hydrogen model to minimize costs of hydrogen. The model returns the optimized locations of electrolyzers, the optimized individual daily production rate at each electrolyzer, the optimized daily transportation volume between each electrolyzer and fueling station, and the resulting costs of hydrogen.

The optimal locations under the uniform tariff are presented as green triangles in Figure 1a. 79 electrolyzers are built to satisfy the demand. The size of the triangles corresponds to production volume. The electrolyzers are placed close to fueling stations and their production rate ranges from 4,900 to 30,100 $\mathrm{kg} /$ day, with a median of $7,000 \mathrm{~kg} /$ day. The total cost and cost shares of all components are shown in Table 4. Production costs represent the most significant share of the total costs, with $62 \%$ in the case of $\mathrm{GH} 2$. Transportation as GH2 leads to lowest total costs. The optimal locations of electrolyzers are identical for the three states of transportation.

Under the nodal tariff, production is more concentrated, as only 29 electrolyzers are built. As depicted in Figure 1b, they are predominantly placed in the North at nodes with particularly low electricity costs. Furthermore, all electrolyzers operate at high production rates. All electrolyzers except three operate at their maximum capacity of $30,100 \mathrm{~kg} / \mathrm{day}$. The high production at low prices leads to a reduction in hydrogen production cost of about $2.2 € / \mathrm{kg}$, compared to the uniform tariff scenario. Meanwhile, the longer transport distances lead to an increase in transportation cost of about $0.6 € / \mathrm{kg}_{H_{2}}$. In total, the nodal tariff can reduce total costs of hydrogen by $1.57 € / \mathrm{kg}_{H_{2}}(32.5 \%)$ in the $\mathrm{GH} 2$ case. Under both tariffs, hydrogen processed and transported as $\mathrm{GH} 2$ has the lowest cost. For all three states of transportation, optimal electrolyzer locations are the same. Production rates are nearly identical, although the higher per-kg transportation costs of LH2 and LOHC lead to slightly lower production at cheap, but remote nodes.

Table 4: Hydrogen cost results [€/ $\mathrm{kg}_{H_{2}}$ ]

\begin{tabular}{l|ccc|ccc}
\hline Tariff & \multicolumn{3}{|c|}{ Uniform Tariff } & \multicolumn{3}{c}{ Nodal Tariff } \\
\hline State & GH2 & LH2 & LOHC & GH2 & LH2 & LOHC \\
\hline \hline$\sum$ & $\mathbf{4 . 8 3}$ & 5.24 & 7.13 & $\mathbf{3 . 2 6}$ & 3.35 & 5.54 \\
\hline PCC & 0.60 & 0.60 & 0.60 & 0.60 & 0.60 & 0.60 \\
CCC & 0.00 & 0.01 & 0.00 & 0.00 & 0.01 & 0.00 \\
TCC & 0.28 & 0.16 & 0.13 & 0.28 & 0.16 & 0.13 \\
SCC & 0.56 & 0.71 & 1.22 & 0.56 & 0.71 & 1.22 \\
POC & 2.98 & 2.98 & 2.98 & 0.83 & 0.81 & 0.81 \\
COC & 0.00 & 0.43 & 0.82 & 0.00 & 0.11 & 0.80 \\
TOC & 0.31 & 0.31 & 0.31 & 0.89 & 0.91 & 0.91 \\
SOC & 0.10 & 0.04 & 1.07 & 0.10 & 0.04 & 1.07 \\
\hline
\end{tabular}

PCC: production capital costs, CCC: conversion capital costs, TCC: transportation capital costs, SCC: fueling station capital costs, POC: production operating costs, COC: conversion operating costs, TOC: transportation operating costs, SOC: fueling station operating costs

To understand better how cost results are affected by capital cost input assumptions, we perform a sensitivity analysis for five key variables. We vary each of them by $+/-20 \%$ and rerun the hydrogen model. The results in Table 5 show by how much this changes the total costs of a GH2 based supply chain. Changes in electrolyzer and fueling station investment costs have the largest effect on total costs. This can be explained by the fact that these two variables are part of the largest absolute capital cost components (compare PCC and SCC in Table 4).

Table 5: Sensitivity analysis: GH2 cost changes

\begin{tabular}{l|c|c}
\hline Input variable & $\begin{array}{c}\text { Uniform } \\
\text { Tariff }\end{array}$ & $\begin{array}{c}\text { Nodal } \\
\text { Tariff }\end{array}$ \\
\hline Electrolyzer investment $\uparrow$ & $+2.47 \%$ & $+3.67 \%$ \\
Fueling station investment $\uparrow$ & $+2.30 \%$ & $+3.42 \%$ \\
WACC $\uparrow$ & $+1.19 \%$ & $+1.77 \%$ \\
Trailer investment $\uparrow$ & $+0.74 \%$ & $+1.09 \%$ \\
Truck investment $\uparrow$ & $+0.43 \%$ & $+0.64 \%$ \\
\hline
\end{tabular}




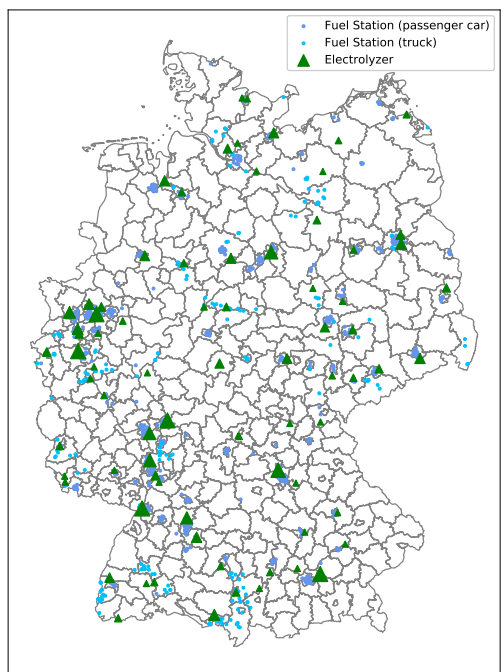

(a) electrolyzers under uniform tariff

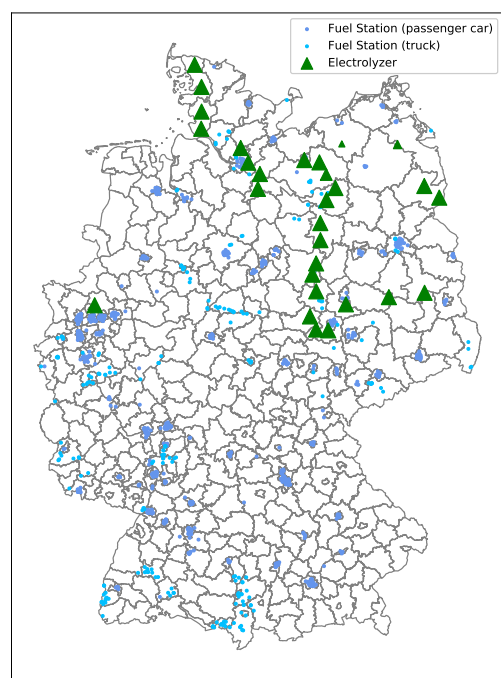

(b) electrolyzers under nodal tariff

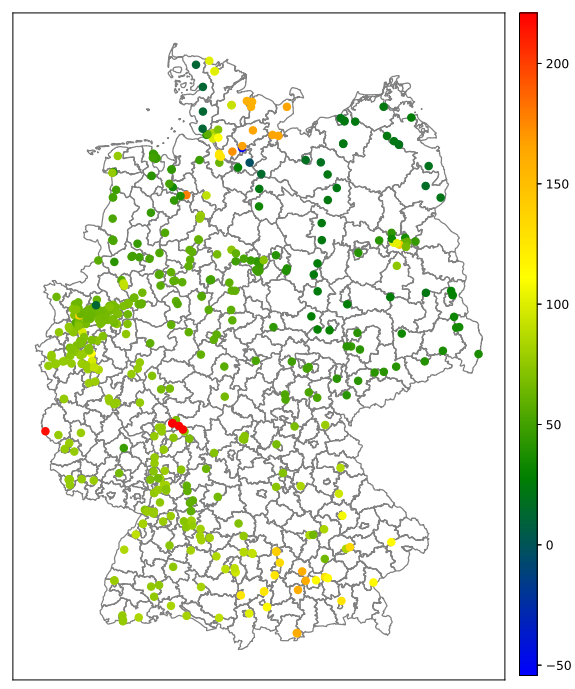

(c) nodal prices [€/MWh]

Figure 1: Optimal electrolyzer locations under two electricity tariffs

\subsection{Feedback effect results}

Finally, we add the electricity demand from hydrogen production to the associated nodes in the electricity system and calculate electricity prices and redispatch costs once again to assess the feedback effect of hydrogen production on the electricity system. For this, we use the cost-minimal GH2 hydrogen supply chain set-up under the two tariff scenarios. As a result, wholesale uniform prices under both uniform and nodal tariff increase by $1.65 € / \mathrm{MWh}$, as shown in Table 6 . Compared to the benchmark scenario, annual redispatch costs increase by $0.17 \mathrm{Bn} €$ under the uniform tariff, and decrease by $0.57 \mathrm{Bn} €$ under the nodal tariff. This represents a delta of $0.74 \mathrm{Bn} €$ per year, or $2.49 € / \mathrm{kg}_{\mathrm{H}_{2}}$.

Table 6: Redispatch costs and uniform prices in 2030

\begin{tabular}{llll}
\hline & No $H_{2}$ & $\begin{array}{l}\text { Uniform } \\
\text { Tariff } H_{2}\end{array}$ & $\begin{array}{l}\text { Nodal } \\
\text { Tariff } H_{2}\end{array}$ \\
\hline $\begin{array}{l}\text { Redispatch } \\
\text { costs [Bn } € \text { ] }\end{array}$ & 6.16 & 6.33 & 5.59 \\
$\begin{array}{l}\text { Uniform price } \\
{[€ / M W h]}\end{array}$ & 62.61 & 64.26 & 64.26 \\
\hline
\end{tabular}

\section{Discussion}

The hydrogen cost results presented above assume that electrolyzers pay only the price of electricity generation. The results are in the range of [9] who report 2.87-3.56€ $€ / \mathrm{kg}_{\mathrm{H}_{2}}$ under this assumption. Adding electricity tax $(0.01537 € / \mathrm{kWh})$, surcharges $(0.0386$ $€ / \mathrm{kWh}$ ), and value added tax $(19 \%)$ at their average 2019 levels [61] increases end-use costs to $7.48 € / \mathrm{kg}_{\mathrm{H}_{2}}$ (Uniform Tariff) and $5.91 € / k g_{H_{2}}$ (Nodal Tariff).

Throughout this study, we make several necessary simplifying assumptions. We assume that electrolyzers can only be installed at transmission grid nodes. For large electrolyzers, this seems justified as they create large loads and thus require connection to sufficiently large power transformers. Smaller scale local hydrogen production at fueling station sites can be an alternative to centralized production $[19,62]$. While beyond the scope of this work, a combined analysis of centralized and decentralized production as well as imports represents an interesting expansion for future research. Besides, we assume a fixed daily hydrogen production rate and do not consider time-flexible operation and storage of hydrogen. This is somewhat in line with [20] who find that electrolyzers should produce in most hours of the year, even under most dynamic electricity tariffs. Nonetheless, allowing time-flexible operation and storage could lead to reductions of hydrogen and redispatch costs. Moreover, our model provides high spatial granularity, at the costs of treating Germany as an isolated system without international transport of electricity or hydrogen. This affects e.g. electricity prices and redispatch. Geographic expansion to a European model seems desirable, but would require substantial additional modelling effort. Finally, future work should analyze in detail the design of a transfer payment mechanism to finance cheaper, spatially differentiated electricity prices for electrolyzers from 
prospective redispatch cost savings.

\section{Conclusion}

Based on the results presented and discussed above, we answer the three research questions posed in Section 2 as follows. The cost-minimal supply chain design for the combined hydrogen demand from passenger cars and heavy-duty trucks in 2030 in Germany requires 79 (uniform tariff) and 29 (nodal tariff) electrolyzers, 917 fueling stations for passenger cars, 247 fueling stations for heavy-duty trucks, and 1164 delivery trucks for gaseous delivery in trailers. The optimal supply chain is strongly influenced by the electricity tariff design. Under the currently prevailing uniform tariff, electrolyzers are cost-minimally placed close to consumption, i.e. in large cities, industrial centers and along highways. Under the nodal tariff, all electrolyzers are installed in the northern part of Germany and hydrogen production is more concentrated at fewer nodes. This leads to longer transportation distances and higher costs for transportation. However, this increase in transportation costs is outweighed by the substantially larger savings through cheaper production. Therefore, total end-use costs of hydrogen are lower under the nodal tariff, with $3.26 € / k_{H_{2}}$ compared to $4.38 € / \mathrm{kg}_{\mathrm{H}_{2}}$ under a uniform tariff. Large-scale electrolysis brings new demand to the electricity grid and affects congestion management. Compared to the benchmark scenario without electrolysis, redispatch costs rise by $0.17 \mathrm{Bn€/year}$ if electrolyzers are placed under the uniform tariff. The cost-minimal supply chain under the nodal tariff is much more system-friendly, as it decreases redispatch costs by $0.57 \mathrm{Bn} € /$ year.

In summary, our work highlights the importance of efficient economic signals, especially spatial signals, in future energy systems. It does so by showing that the cost-minimal design of hydrogen supply chains, including the location of electrolyzers and transportation routes, highly depends on the spatial granularity of the electricity tariff. Nodal tariffs reduce both end-use costs for hydrogen and redispatch costs. For further progress towards political implementation, future work should investigate in detail how nodal tariffs for electrolyzers - or related incentive mechanisms such as spatially differentiated subsidies - can be financed through transfer payments from avoided redispatch costs.

\section{References}

[1] Center for Climate and Energy Solutions, "Global emissions," 2020.

[2] International Energy Agency, "Tracking transport," 2019.
[3] Bundesministerium für Umwelt, Naturschutz und nukleare Sicherheit, "Klimaschutzprogramme 2030," 2019.

[4] Federal Government of Germany, "Die Nationale Wasserstoffstrategie," 2020.

[5] M. Reuß, T. Grube, M. Robinius, and D. Stolten, "A hydrogen supply chain with spatial resolution: Comparative analysis of infrastructure technologies in Germany," Applied Energy, 2019.

[6] European Commission, "A hydrogen strategy for a climate-neutral europe," 2020.

[7] A. Almansoori and N. Shah, "Design and Operation of a Future Hydrogen Supply Chain: Snapshot Model," Chemical Engineering Research and Design, 2006.

[8] C. Yang and J. M. Ogden, "Renewable and low carbon hydrogen for california - modeling the long term evolution of fuel infrastructure using a quasi-spatial times model," International Journal of Hydrogen Energy, 2013.

[9] A. Almansoori and A. Betancourt-Torcat, "Design of optimization model for a hydrogen supply chain under emission constraints - a case study of Germany," Energy, 2016.

[10] A. Almansoori and N. Shah, "Design and operation of a stochastic hydrogen supply chain network under demand uncertainty," International Journal of Hydrogen Energy, 2012.

[11] S. Samsatli, I. Staffell, and N. J. Samsatli, "Optimal design and operation of integrated wind-hydrogen-electricity networks for decarbonising the domestic transport sector in Great Britain," International Journal of Hydrogen Energy, 2015.

[12] F. Heymann and R. Bessa, "Power-to-Gas potential assessment of Portugal under special consideration of LCOE," in 2015 IEEE Eindhoven PowerTech, 2015.

[13] H. Talebian, O. E. Herrera, and W. Mérida, "Spatial and temporal optimization of hydrogen fuel supply chain for light duty passenger vehicles in british columbia," International Journal of Hydrogen Energy, 2019.

[14] L. Welder, D. S. Ryberg, L. Kotzur, T. Grube, M. Robinius, and D. Stolten, "Spatio-temporal optimization of a future energy system for power-to-hydrogen applications in Germany," Energy, 2018.

[15] M. Robinius, A. Otto, P. Heuser, L. Welder, K. Syranidis, D. Ryberg, T. Grube, P. Markewitz, R. Peters, and D. Stolten, "Linking the power and transport sectors-part 1: The principle of sector coupling," Energies, 2017.

[16] B. Emonts, M. Reuß, P. Stenzel, L. Welder, F. Knicker, T. Grube, K. Görner, M. Robinius, and D. Stolten, "Flexible sector coupling with hydrogen: A climate-friendly fuel supply for road transport," International Journal of Hydrogen Energy, 2019.

[17] European parliament and European council, "Regulation (ec) no 1059/2003," 2003.

[18] P. Runge, C. Sölch, J. Albert, P. Wasserscheid, G. Zöttl, and V. Grimm, "Economic comparison of different electric fuels for energy scenarios in 2035," Applied Energy, 2019.

[19] P. K. Rose and F. Neumann, "Hydrogen refueling station networks for heavy-duty vehicles in future power systems," Transportation Research Part D: Transport and Environment, vol. 83, 2020. 
[20] O. J. Guerra, J. Eichman, J. Kurtz, and B.-M. Hodge, "Cost competitiveness of electrolytic hydrogen," Joule, 2019.

[21] K. Trepper, M. Bucksteeg, and C. Weber, "Market splitting in Germany - New evidence from a three-stage numerical model of Europe," Energy Policy, 2015.

[22] D. Teichmann, W. Arlt, and P. Wasserscheid, "Liquid organic hydrogen carriers as an efficient vector for the transport and storage of renewable energy," International Journal of Hydrogen Energy, 2012.

[23] M. Reuß, Techno-ökonomische Analyse alternativer Wasserstoffinfrastruktur. PhD thesis, RWTH Aachen, 2019.

[24] G. Glenk and S. Reichelstein, "Economics of converting renewable power to hydrogen," Nature Energy, 2019.

[25] Fraunhofer-Institut, "Eine Wasserstoff-Roadmap für Deutschland," 2019.

[26] European Alternative Fuels Observatory, "European classification for vehicle category."

[27] T. Grube and D. Stolten, "The impact of drive cycles and auxiliary power on passenger car fuel economy," Energies, 2018.

[28] M. Patrick and H. Damon, "Prospects for hydrogen as a transport fuel," International Journal of Hydrogen Energy, 2019.

[29] FCH-JU, "Development of business cases for fuel cells and hydrogen applications for regions and cities," 2017.

[30] Kraftfaht-Bundesamt, "Verkehr in Kilometern Inländerfahrleistung,” 2018.

[31] Kraftfahrt-Bundesamt, "Bestand an Kraftfahrzeugen und Kraftfahrzeuganhängern nach Zulassungsbezirken (FZ 1), 1. Januar 2019," 2019.

[32] SAE MOBILUS, "Fueling protocols for light duty gaseous hydrogen surface vehicles," 2016.

[33] SAE MOBILUS, "Fueling protocol for gaseous hydrogen powered heavy duty vehicles," 2014.

[34] NOW GmbH, "Operation of a fully-integrated, public hydrogen refueling station," 2011.

[35] International Energy Agency, "Large-scale hydrogen delivery infrastructure," 2015.

[36] H2 MOBILITY, “Tankstellen.” Retrieved from https : //h2.live/en/tankstellen, 2019.

[37] OpenStreetMap Contributors, "OpenStreetMap data for Germany," 2020.

[38] Statistisches Bundesamt, "Gemeindeverzeichnis," 2019.

[39] Bundesamt für Kartographie und Geodäsie, "Digitales Landschaftsmodell 1:1 000000 (Ebenen) (DLM1000)," 2019.

[40] T. Smolinka, M. Günther, and J. Garche, "NOW-Studie: Stand und Entwicklungspotenzial der Wasserelektrolyse zur Herstellung von Waserstoff aus regenerativen Energien," 2011.

[41] S. Schiebahn, T. Grube, M. Robinius, V. Tietze, B. Kumar, and D. Stolten, "Power to gas: Technological overview, systems analysis and economic assessment for a case study in Germany," International Journal of Hydrogen Energy, 2015.

[42] O. Schmidt, A. Gambhir, I. Staffell, A. Hawkes, J. Nelson, and S. Few, "Future cost and performance of water electrolysis: An expert elicitation study," International Journal of Hydrogen Energy, 2017.
[43] T. Brown, D. Schlachtberger, A. Kies, S. Schramm, and M. Greiner, "Synergies of sector coupling and transmission reinforcement in a cost-optimised, highly renewable european energy system," Energy, 2018.

[44] NOW GmbH, "Industrialisierung der Wasserelektrolyse in Deutschland: Chancen und Herausforderungen für nachhaltigen Wasserstoff für Verkehr, Strom und Wärme," 2018.

[45] ITM-Power, "5 min elevator pitch - hydrogen + fuel cells europe," 2017.

[46] Shell, "Shell nutzfahrzeug-studie diesel oder alternative antriebe - womit fahren lkw und bus morgen?," 2016.

[47] K. Reddi, M. Mintz, A. Elgowainy, and E. Sutherland, Challenges and Opportunities of Hydrogen Delivery via Pipeline, Tube-Trailer, Liquid Tanker and Methanation-Natural Gas Grid. John Wiley \& Sons, Ltd, 2016.

[48] P. Staudt and S. Oren, "A merchant transmission approach for uniform-price electricity markets," in Proceedings of the 53rd Hawaii International Conference on System Sciences, 2020.

[49] J. Egerer, "Open source Electricity Model for Germany (ELMOD-DE)," DIW Data Documentation 83, German Institute for Economic Research (DIW), Berlin, 2016.

[50] F. vom Scheidt, C. Müller, P. Staudt, and C. Weinhardt, "The German Electricity System in 2030: Data on Consumption, Generation, and the Grid." Karlsruhe Institute of Technology, https://bwdatadiss . kit. edu/dataset/254, 2020.

[51] C. Matke, W. Medjroubi, and D. Kleinhans, "SciGRID - An Open Source Reference Model for the European Transmission Network (v0.2)," July 2016.

[52] Bundesnetzagentur, "Bestätigung des Netzentwicklungsplans Strom für das Zieljahr 2030,” 2019.

[53] F. Kießling, P. Nefzger, and U. Kaintzyk, Freileitungen: Planung, Berechnung, Ausführung. Springer-Verlag, 2011.

[54] European Network of Transmission System Operators for Electricity, "Transparency Platform." Retrieved from https://tyndp. ent soe.eu/maps-data, 2018.

[55] M. Robinius, F. Stein, S. Schienahn, and D. Stolten, "Lastmodellierung und -visualisierung mittels geoinformationssystemen," in Proceedings of Symposium Energieinnovation, 2014.

[56] ifo Institut, "Prognose der wirtschaftlichen Entwicklung 2010 bis 2030," 2012.

[57] Bundesnetzagentur, "Marktdaten." Retrieved from https: //www.smard.de/, 2018.

[58] Deutsche Übertragungsnetzbetreiber, "EEG-Anlagenstammdaten," 2018.

[59] Bundesnetzagentur, "Bnetza-power-plant-list," 2019.

[60] Bundesministerium für Wirtschaft und Energie, "Evaluierung der Kraft-Wärme-Kopplung," 2019.

[61] BDEW Bundesverband der Energie-und Wasserwirtschaft e.V., "BDEW-Strompreisanalyse Januar 2020,” 2020.

[62] A. Golla, F. vom Scheidt, N. Röhrig, P. Staudt, and C. Weinhardt, "Vehicle scheduling and refuelling of hydrogen buses with on-site electrolysis," Jahrestagung der Gesellschaft für Informatik 2020, 2020. 